96 THE RELATIONSHIP BETWEEN HOPE, SOCIAL INCLUSION AND MENTAL WELLBEING IN SUPPORTED WORK INTEGRATION

Debra A Dunstan*, Amanda K Falconer, lan R Price. School of Behavioural, Cognitive and Social Sciences, University of New England, Armidale, NSW

10.1136/oemed-2018-ICOHabstracts. 1589

Introduction Mental health services in developed nations have a recovery orientation. In this context, 'recovery' does not mean being symptom-free, but instead indicates that a person is 'living a satisfying, hopeful and contributing life even with the limitations caused by illness' (Anthony, 1993; p. 975). Australia's Fourth National Mental Health Plan sets social inclusion as its first priority and prescribes work integration as a key action and outcome by which people with mental illness achieve both social and economic inclusion. Research has identified the core components of recovery as: hope, social inclusion or connexion, empowerment and wellbeing, with 'hope' being the first and central requirement. This study explored the relationships between hope, social inclusion and mental wellbeing in a sample of people in recovery from mental illness.

Methods Participants were 70 adults (60\% male) with a psychiatric disability $(71.4 \%$ schizophrenia) who were engaged in supported employment (i.e., they were receiving a productivity-based wage). All completed a battery of psychometric measures and open-ended questions.

Result Compared to clinical samples of people diagnosed with a mental disorder, the participants in this study had higher levels of hope, social inclusion and mental wellbeing, and lower levels of psychological distress. Hope and social inclusion predicted mental wellbeing, with social inclusion partially mediating the relationship between the other two constructs. Participants reported experiencing the psychosocial benefits of work (e.g., structured activity and a shared purpose) but were dissatisfied with their wages.

Discussion Work integration through supported employment provides an opportunity for social inclusion and the prevention of long-term work disability. Engagement in work significantly mediates recovery from severe mental illness and facilitates a healthy level of mental wellbeing. Work integration can be achieved in the presence of ongoing symptoms and despite the absence of full economic inclusion. Australian health policy is supported.

\section{INTERDISCIPLINARY COMMITTEE TO SUPPORT EMPLOYEES WITH WORK RESTRICTIONS IN A PUBLIC HYDROELECTRIC POWER PLANT IN BRAZIL}

FC Schveitzer, GLP Hoppe, CPG Svoboda, WOA Braga, APD Trevisan. Itaipu Binacional, Foz do lguaçu, Brazil

\subsection{6/oemed-2018-ICOHabstracts.1590}

Introduction Ageing population and the increasing of job complexity elucidate the challenge of social and business politics to maintain employee fitness to work and to provide access to occupational rehabilitation for employees with work restrictions. The objective of this study is to describe the results of an interdisciplinary committee organised in a public company in Brazil in order to support the rehabilitation of employees with work restrictions.
Methods A retrospective study was conducted on occupational health records of all 69 employees with work restrictions accompanied by the interdisciplinary committee between 2009 and 2017 in a hydroelectric power plant in Brazil. The committee was composed by 2 occupational physicians, 1 occupational health nurse, 1 organisational psychologist and 1 social worker. The information analysed was gender, illness, sickness absence, conducts achieved and agreement between suggested committee approach and conduct adopted by the National Institute of Social Security (INSS).

Result From the 69 employees, 51 (73,9\%) were men and 18 $(26,1 \%)$ women. The most frequent group of diseases were related to musculoskeletal and connective tissue $(33,3 \%)$, followed by mental disorders group $(28,9 \%)$, consequences of external causes $(10,1 \%)$ and neoplasms $(8,7 \%)$. The most frequent diagnoses were back pain $(11,5 \%)$ and depression $(7,2 \%)$. From the total, $20,2 \%$ of workers had no sickness absence during follow-up. Conducts achieved were $46,3 \%$ of workers exercising their same activities as before the attendance committee, $24,6 \%$ rehabilitated for different activities, and $20,2 \%$ retired due to disability. There was an agreement by the INSS for all 21 suggested committee approachs, distributed between disability retirement (14) and occupational rehabilitation (7).

Discussion The establishment of the interdisciplinary committee led the company to a better management of workers' health restrictions. Also, the committee improved the conduction of the occupational rehabilitation process, considering the agreement by the INSS in all cases.

\section{Work Organisation and Psychosocial Factors}

\section{PREDICTING EMPLOYEE'S HEALTH AND WELLBEING: FINDINGS FROM A MASS EMPLOYEES HEALTH SCREENING PROGRAM IN MALAYSIA}

Azlan Darus*, Mohammed Azman Aziz Mohammed. Social Security Organisation, Malaysia

\subsection{6/oemed-2018-ICOHabstracts.1591}

Introduction The Social Security Organisation of Malaysia is a statutory body responsible for social security protection to employees in Malaysia against occupational injury and diseases, and total inability to earn any income. In the year 2013, SOCSO had embarked on a health promotion campaign to its insured persons by providing free health screening to all insured persons aged 40 years old and above. Until the time of writing, 2.4 million insured persons were eligible and offered the health screening program.

Methodology Presence of cardiovascular risk factors and diseases such as diabetes, hypertension, hypercholesterolaemia and body mass index were obtained from the health screening data Cardiovascular risk factors were determined through Framingham risk scoring computed from the available health parameters.

Results A total of 472093 employee health screening data were available for analysis. There were 53\% male compared to $47 \%$ female. Among the males, $30 \%$ had indicated that they are current smokers, compared to $1 \%$ among women. The prevalence of overweight, obesity, hypertension, diabetes and hypercholesterolaemia were 39\%, 34\%, 27\%,9\% and $62 \%$ respectively. More than 9800 women were found with highly suspicious mammogram, with 164 found with findings highly suggestive of breast malignancy. Meanwhile, nearly 500 